$03,09,12$

\title{
Магнитная циркулярная поляризация фотолюминесценции экситонов
}

\author{
() Е.Л. Ивченко \\ Физико-технический институт им. А.Ф. Иофрфе РАН, \\ Санкт-Петербург, Россия \\ E-mail: ivchenko@coherent.ioffe.ru
}

\begin{abstract}
Дан обзор экспериментальных и теоретических исследований циркулярной поляризации фотолюминесценции экситонов в полупроводниках во внешнем магнитном поле. Преимуществом методики МЦПЛ является ее относительная простота. В частности, она не требует спектрального разрешения зеемановских подуровней экситона и может быть применена к широкому классу объектов со спектрально широкими линиями или полосами ФЛ: в объемных полупроводниках с экситонами, локализованными на дефектах кристаллической решетки и флуктуациях состава, в структурах с квантовыми ямами и квантовыми точками типа I и II, двумерных дихалькогенидах переходных металлов и квантовых микрорезонаторах. Рассмотрены основные механизмы магнитной циркулярной поляризации люминесценции. Показано, что для описания поляризованной фотолюминесценции в появляющихся новых наносистемах приходится или модифицировать установленные механизмы, или разрабатывать дополнительные механизмы МЦПЛ.
\end{abstract}

Работа выполнена при поддержке Российского научного фонда (проект 14-12-01067).

DOI: $10.21883 /$ FTT.2018.08.46237.04Gr

\section{1. Введение}

Вскоре после пионерских работ по экситонам Я.И. Френкель предсказал, что в кристалле могут быть экситоны двух типов, названные им „свободными“ и „прилипшими“ [1]. В случае экситона второго типа возникает локальная деформация решетки, которая может сильно уменьшить групповую скорость распространения электронного возбуждения или сделать это возбуждение неподвижным. Идея о двух типах экситонов развивалась также в работах Давыдова [2] („волны возбуждения типа А и В“) и Дыкмана и Пекара [3] („неполяризующий“ и „поляризующий“ экситоны), см. также обзор [4]. От понятия „прилипшего“ или „Поляризующего“ экситона, позднее названного автолокализованным [5], остается один шаг до экситона, локализованного на дефекте решетки: на ионизованном или нейтральном доноре или акцепторе, на изоэлектронной ловушке, - и другим неподвижным экситонным комплексам [6-11]. В магнитном поле узкие линии фотолюминесценции (ФЛ) таких комплексов расщепляются, их тонкая структура может быть разрешена и спектрально, и поляризационно. В настоящей статье рассматриваются объемные и низкоразмерные твердотельные системы, в которых из-за неоднородного уширения резонансной частоты экситона, ширина полосы экситонной люминесценции намного превосходит обменное и зеемановское расщепления экситонных уровней. Именно такая ситуация возникает при локализации экситонов на глубоких уровнях в объемных кристаллах [12] или флуктуациях состава в твердых растворах [13], на флуктуациях толщины квантовой ямы $[14,15]$ или площади сечения квантовой проволоки, на интерфейсах сверхрешетки типа II [16], а также при размерном квантовании экситонов в квантовых точках [17] или коллоидных нанокристаллах $[18,19]$ с учетом разброса их размеров и формы в области пятна засветки. Эта спектрально скрытая тонкая структура проявляется в магнитной циркулярной поляризации люминесценции (МЦПЛ) и зависимости интенсивности люминесценции от величины магнитного поля.

Статья построена следующим образом. В разд. 2 рассмотрено изменение энергетического спектра локализованного экситона в продольном магнитном поле. В разд. 3 приведены формулы для интенсивности и циркулярной поляризации фотолюминесценции в простейшей квазиравновесной модели в пренебрежении обменным взаимодействием, обсуждается антипересечение экситонных подуровней при учете этого взаимодействия и дан обзор экспериментальных работ по изучению МЦПЛ в объемных полупроводниковых кристаллах, твердых растворах и наноструктурах. В разд. 4 представлены результаты недавно опубликованных работ [20-22] по изучению МЦПЛ в ультратонкой квантовой яме GaAs/AlAs с гетеропереходом типа II и непрямой запрещенной зоной. Магнитолюминесценция экситонов и трионов в квантовых ямах и двумерных дихалькогенидах переходных металлов обсуждается в разд. 5. В отдельный разд. 6 вынесено рассмотрение МЦПЛ экситонных магнитных поляронов в магниторазбавленных полупроводниках и экситонных поляритонов в микрорезонатоpax, а также параэкситонов в кристаллах закиси меди [23], в которых были впервые обнаружены экситоны Ванье-Мотта [24].

\section{2. Перестройка тонкой структуры экситонов в продольном магнитном поле}

С учетом спина свободных носителей, но в пренебрежении электронно-дырочным обменным взаимодей- 
ствием, основной уровень экситона вырожден. Вырожденные состояния образуют базис некоторого представления $D_{\text {exc }}$, размерности больше 1 , точечной группы симметрии $F$ локализующего потенциала. Обменное взаимодействие частично снимает вырождение экситонного уровня и приводит к его расщеплению на подуровни, отвечающие неприводимым представлениям группы $F$. В продольном магнитном поле происходит дополнительная перестройка экситонного спектра, в частности, снимается сохраняющееся вырождение экситонных состояний. Каждое из расщепившихся, оптически активных состояний излучает в направлении магнитного поля циркулярно или эллиптически поляризованный свет. Поэтому при селективном заселении этих состояний фотолюминесценция становится циркулярно поляризованной. В данном разделе мы рассмотрим два наиболее часто встречающиеся вида экситонов: экситон с тяжелой дыркой (краткое обозначение $X_{e-h h}$ ) и триплетный экситон $X_{\text {trip. }}$.

А. Экситон с тяжелой дыркой. Модель экситона $X_{e-h h}$, образованного из электрона в зоне проводимости со спином $s= \pm 1 / 2$ и тяжелой дырки с проекцией углового момента $j= \pm 3 / 2$, см. например обзор [25], применима для анализа излучения локализованных экситонов в квантовых ямах и квантовых точках, выращенных на основе полупроводников $\mathrm{A}_{3} \mathrm{~B}_{5}$ или $\mathrm{A}_{2} \mathrm{~B}_{6}$, в сверхрешетках GaAs/AlAs типа I или II, а также в объемных твердых растворах $\mathrm{CdS}_{1-x} \mathrm{Se}_{x}$. Если специально не оговорено, в данной статье рассматривается геометрия, в которой магнитное поле приложено по нормали $z$ к внешней поверхности образца и изучается интенсивность и поляризация света, излучаемого в направлении $z$.

Спин-гамильтониан $\mathscr{H}_{\text {exc }}=E_{0}+\mathscr{H}_{\text {exch }}+\mathscr{H}_{B}$ экситона $X_{e-h h}$ содержит оператор обменного взаимодействия [26]

$$
\mathscr{H}_{\text {exch }}=\frac{1}{2}\left[\begin{array}{cccc}
\delta_{0} & \delta_{2} & 0 & 0 \\
\delta_{2} & \delta_{0} & 0 & 0 \\
0 & 0 & -\delta_{0} & \delta_{1} \\
0 & 0 & \delta_{1} & -\delta_{0}
\end{array}\right]
$$

и оператор зеемановского взаимодействия электронного и дырочного спинов с продольным магнитным полем

$$
\begin{aligned}
& \mathscr{H}_{B}=\frac{1}{2} \mu_{B} B_{z} \\
& \times\left[\begin{array}{cccc}
-g_{e}+g_{h h} & 0 & 0 & 0 \\
0 & g_{e}-g_{h h} & 0 & 0 \\
0 & 0 & g_{e}+g_{h h} & 0 \\
0 & 0 & 0 & -g_{e}-g_{h h}
\end{array}\right] .
\end{aligned}
$$

Здесь $E_{0}-$ энергия возбуждения „механического“ экситона, матричные элементы представлены в базисе экситонных состояний $|m\rangle$ с заданной проекцией полного спина $m=s+j=1,-1,2,-2$, константы $\delta_{n}(n=0,1,2)$ описывают соответственно дублетдублетное расщепление и расщепления нерадиационного (или „темного“, $m= \pm 2$ ) и радиационного (или

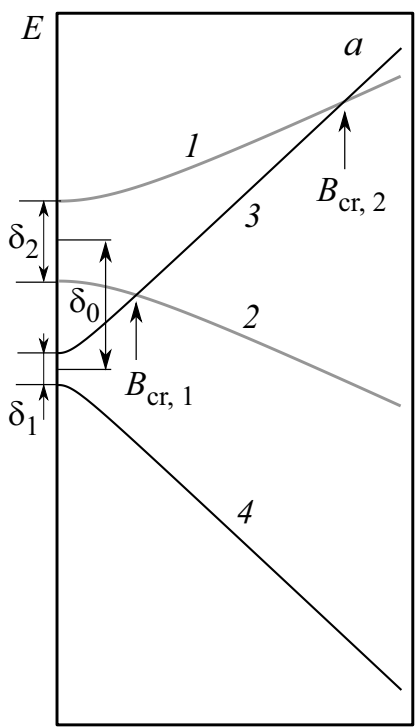

Magnetic field

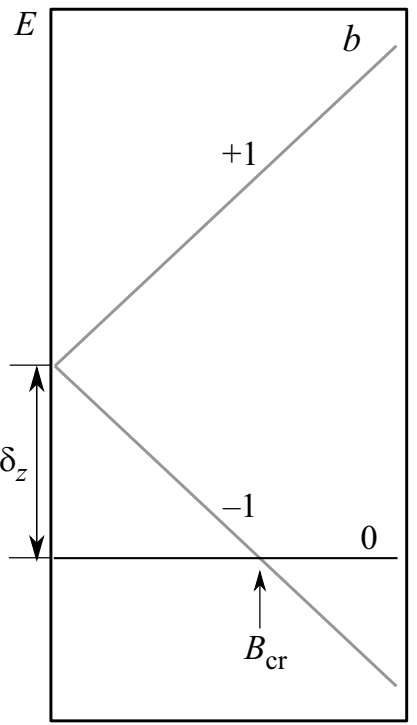

Magnetic field
Рис. 1. Зависимость энергии подуровней экситона с тяжелой дыркой $X_{e-h h}(a)$ и триплетного экситона $X_{\text {trip }}(\mathrm{b})$ от продольного магнитного поля. Вертикальными стрелками отмечены критические магнитные поля $B_{\text {cr }}$, при которых происходит пересечение спиновых подуровней.

„светлого“, $m= \pm 1)$ дублетов, $\mu_{B}$ - магнетон Бора, $g_{e}$ и $g_{h h}$ - эффективные $g$-факторы электрона и тяжелой дырки. Для наноструктур, выращенных в направлении $z$ \| [001], матричные элементы оптического возбуждения базисных состояний $|m\rangle$ имеют вид

$$
M_{ \pm 1}=M_{0}\left(e_{x} \pm \mathrm{i} e_{y}\right), \quad M_{ \pm 2}=0
$$

где $e_{x}, e_{y}$ - латеральные компоненты вектора поляризации света в осях $x\|[110], y\|[\overline{1} 10], M_{0}-$ не зависящий от поляризации коэффициент. В магнитном поле положение подуровней квартета определяется выражениями

$$
\begin{gathered}
E_{1,2}=E_{0}+\frac{1}{2}\left(\delta_{0} \pm \sqrt{\delta_{2}^{2}+\left(g_{e}-g_{h h}\right)^{2} \mu_{B}^{2} B_{z}^{2}}\right), \\
E_{3,4}=E_{0}+\frac{1}{2}\left(-\delta_{0} \pm \sqrt{\delta_{1}^{2}+\left(g_{e}+g_{h h}\right)^{2} \mu_{B}^{2} B_{z}^{2}}\right) .
\end{gathered}
$$

Зависимость энергии этих подуровней от магнитного поля схематически представлена на рис. $1, a$, там же указаны расщепления $\delta_{n}$.

В. Триплетный экситон. Эта модель применима к экситонным квартетам, в которых главную роль в обменном взаимодействии играет синглет-триплетное расщепление $\Delta_{\mathrm{S}-\mathrm{T}}$, которое велико по сравнению с анизотропным расщеплением триплетных состояний с проекциями полного спина электронно-дырочной пары $S= \pm 1$ и $S=0$. Это позволяет рассматривать синглетный и триплетный экситоны по отдельности. В продольном магнитном поле спиновый гамильтониан триплетного 
экситона $X_{\text {trip }}$ принимает вид

$$
\mathscr{H}_{\mathrm{exc}}=E_{0}+\delta_{z}\left(S_{z}^{2}-\frac{2}{3}\right)+\delta_{x y}\left(S_{x}^{2}-S_{y}^{2}\right)+g_{\text {tr }} \mu_{B} B_{z} S_{z},
$$

где $S_{\alpha}$ - матрицы (размерности $3 \times 3$ ) углового момента $S=1, \delta_{z}$ и $\delta_{x y}$ - обменные константы, $g_{\text {tr }}-g$-фактор триплетного экситона. При аксиальной симметрии центра локализации константа $\delta_{x y}$ равна нулю и три подуровня триплета имеют энергии, см. рис. $1, b$,

$$
E_{ \pm 1}=E_{0}+\frac{\delta_{z}}{3} \pm g_{\mathrm{tr}} \mu_{B} B_{z}, \quad E_{0}=E_{T}-\frac{2 \delta_{z}}{3} .
$$

\section{3. МЦПЛ в объемных твердых растворах и наноструктурах}

Перед тем как приступить к обсуждению результатов экспериментального и теоретического исследования МЦПЛ в твердотельных системах, мы приведем формулы для интенсивности и циркулярной поляризации фотолюминесценции экситонов в простейшем случае, когда a) обменным расщеплением уровней экситонного квартета $X_{e-h h}$ и экситонного триплета $X_{\text {trip }}$ пренебрегается и б) время спиновой релаксации между подуровнями намного короче времени жизни экситона, так что заселенности зеемановских подуровней квазиравновесны и относительная вероятность найти экситон в состоянии $m$ равна

$$
f_{m}=\frac{\exp \left(-\frac{E_{m}}{k_{B} T}\right)}{\sum_{m^{\prime}} \exp \left(-\frac{E_{m^{\prime}}}{k_{B} T}\right)},
$$

где $T$ - температура образца, $k_{B}$ - постоянная Больцмана, $m$ и $m^{\prime}= \pm 1, \pm 2$ для экситона $X_{e-h h}$ и $m= \pm 1,0$ для экситона $X_{\text {trip. }}$ В этом случае интенсивность $I$ и степень циркулярной поляризации $P_{c}$ излучения определяются формулами

$I=C_{I} \frac{F\left(B_{z}\right)}{2 \tau_{r} / \tau_{n r}+F\left(B_{z}\right)} G, \quad P_{\mathrm{c}}=\tanh \left[\frac{\left(g_{e}-g_{h h}\right) \mu_{B} B_{z}}{2 k_{B} T}\right]$

для экситона с тяжелой дыркой и

$$
I=C_{I}^{\prime} \frac{F^{\prime}\left(B_{z}\right)}{\left(3 \tau_{r} / 2 \tau_{n r}\right)+F^{\prime}\left(B_{z}\right)} G, \quad P_{\mathrm{c}}=-\tanh \left(\frac{g_{\mathrm{tr}} \mu_{B} B_{z}}{k_{B} T}\right)
$$

для триплетного экситона. Здесь $C_{I}$ и $C_{I}^{\prime}-$ коэффициенты, не зависящие от магнитного поля, $G$ - темп генерации экситонов,

$$
\begin{gathered}
F\left(B_{z}\right)=1-\tanh \left(\frac{g_{e} \mu_{B} B_{z}}{2 k_{B} T}\right) \tanh \left(\frac{g_{h h} \mu_{B} B_{z}}{2 k_{B} T}\right), \\
F^{\prime}\left(B_{z}\right)=\frac{3 \cosh \left(\frac{g_{\mathrm{tr}} \mu_{B} B_{z}}{k_{B} T}\right)}{1+2 \cosh \left(\frac{g_{\mathrm{tr}} \mu_{B} B_{z}}{k_{B} T}\right)},
\end{gathered}
$$

и введены излучательное и безызлучательное времена жизни экситона $\tau_{r}$ и $\tau_{n r}$. Предполагается, что время $\tau_{n r}$ не зависит от состояния экситона $m$ и, в случае триплетного экситона, состояние $|0\rangle$ оптически неактивно. С ростом магнитного поля поляризация стремится к 100\%, ее знак определяется знаком произведения $\left(g_{e}-g_{h h}\right) B_{z}$ или $g_{\operatorname{tr}} B_{z}$.

Предельное значение $100 \%$ достижимо при отсутствии анизотропии в плоскости, перпендикулярной магнитному полю. Случаи нарушенной аксиальной симметрии требуют особого рассмотрения. Один из таких случаев реализуется в структурах без общего катиона и аниона $\mathrm{ZnSe} / \mathrm{BeTe}$, в которых гетеропереход (001) относится к типу II и вклад в ФЛ вносит непрямой экситон, образованный из электрона и дырки, размерноквантованных в соседних слоях $\mathrm{ZnSe}$ и ВеТе. Из-за анизотропии химических связей на интерфейсах (001) матричные элементы оптических междузонных переходов в поляризациях $[1 \overline{1} 0]$ и [110] различны и излучение экситонов в направлении [001] линейно поляризовано со степенью поляризации $P_{l} \sim 0.6$ [27]. В продольном магнитном поле к линейной поляризации ФЛ добавляется циркулярная поляризация $P_{c}$. Так как полная степень поляризации $P=\sqrt{P_{l}^{2}+P_{c}^{2}}$ не превышает единицы, то предельное значение циркулярной поляризации в сильном магнитном поле не может быть больше $\sqrt{1-P_{l}^{2}}=0.8$ в согласии с экспериментом; для прямых оптических переходов предельное значение $P_{c}$ было близко к $100 \%$ [27].

А. Антипересечение экситонных уровней в магнитном поле. В простейшем случае квазиравновесного распределения по подуровням и в пренебрежении обменным взаимодействием интенсивность $I$ и степень поляризации $P_{c}$ являются монотонными функциями магнитного поля. Совсем иначе ведут себя функции $I\left(B_{z}\right), P_{c}\left(B_{z}\right)$ при учете обменного взаимодействия. Дело в том, что при $\delta_{n} \neq 0\left(\delta_{z} \neq 0\right)$ при определенных значениях магнитного поля энергии некоторой пары уровней сравниваются. Так, для экситона $X_{e-h h}$ с $\delta_{0}>0$ и $\delta_{1}=\delta_{2}=0$ пересечение уровней происходит при следующих значениях модуля магнитного поля $B \equiv\left|B_{z}\right|$ :

$$
B_{\mathrm{c} r}=\frac{\delta_{0}}{2 \mu_{B}}\left\{\begin{array}{ll}
g_{e}^{-1}, g_{h h}^{-1}, & \text { если } g_{e}+g_{h h}>0, \\
-g_{e}^{-1},-g_{h h}^{-1}, & \text { если } \left.g_{e}+g_{h h}<0\right) .
\end{array},\right.
$$

где в правой части нужно оставить только положительные величины $B_{\mathrm{cr}, 1}$ и $B_{\mathrm{cr}, 2}$. Поэтому при одинаковых знаках $g_{e}$ и $g_{h h}$ один из нижних подуровней \pm 2 пересекает по очереди два верхних подуровня, а если знаки $g_{e}$ и $g_{h h}$ противоположны, то один из верхних подуровней пересекает нижние подуровни. Выражения для критических значений $B_{\mathrm{cr}, 1}, B_{\mathrm{cr}, 2}$ при $\delta_{1}, \delta_{2} \neq 0$ приведены в [26]. Кривые на рис. 1, $a$ построены для значений $g_{e}$ и $g_{h h}$ одного знака. В триплетном экситоне $X_{\text {trip }}$ пересечение одного из подуровней $| \pm 1\rangle$ с подуровнем $|0\rangle$ происходит при одном значении магнитного поля, рис. $1, b$,

$$
B_{\mathrm{cr}}=\left|\delta_{z} / g_{\mathrm{tr}} \mu_{B}\right|
$$



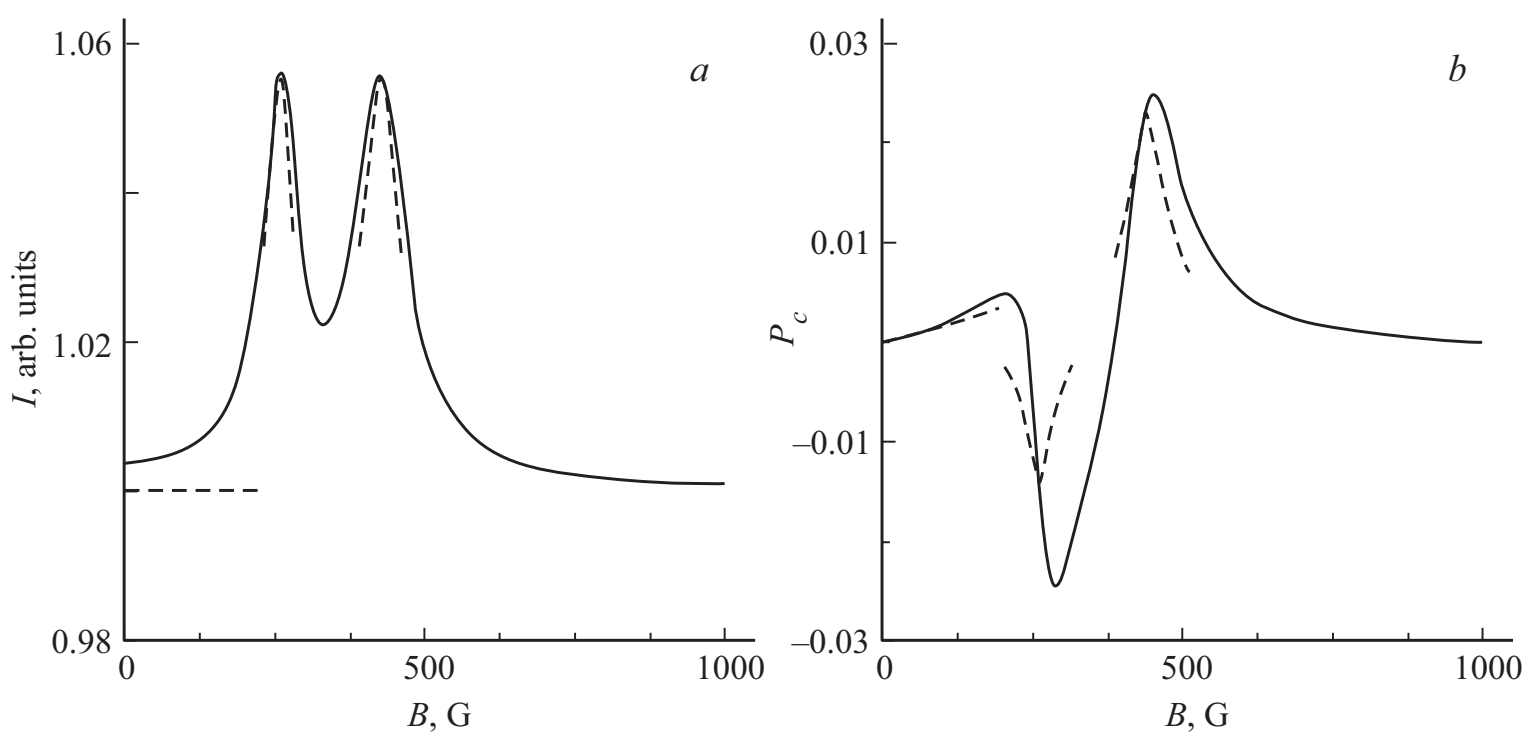

Рис. 2. Зависимости полной интенсивности $(a)$ и степени циркулярной поляризации $(b)$ экситонной люминесценции в сверхрешетке GaAs/AlAs типа II от продольного магнитного поля $B_{z}$. Сплошная кривая - точный расчет, штриховые линии расчет в приближении изолированной пары уровней или в области малых полей. Использовались следующие значения параметров: $\delta_{0}=4.5 \mu \mathrm{eV}, \delta_{1}=0, \delta_{2}=2 \mu \mathrm{eV},\left|V_{e}\right|=0.3 \mu \mathrm{eV}, V_{h}=0, g_{e}=2.08, g_{h h}=0.83, G_{r} / G_{0}=2, \tau_{n r} / \tau_{r}=4$, спиновой релаксацией пренебрегалось. [26]

Даже малое возмущение, понижающее симметрию системы, приводит к сильному резонансному смешиванию сблизившихся уровней, т.е. к их антипересечению, и существенно влияет на интенсивность и поляризацию люминесценции. Это будет особенно проявляться при замедленной спиновой релаксации экситона, когда заселенность экситонных подуровней далека от квазиравновесной и нерадиационных экситонов накапливается больше, чем радиационных. При антипересечении оптически активного и неактивного подуровней возникают смешанные состояния с сохраняющейся суммарной силой осциллятора, но с бо́льшим временем жизни. Поэтому полная интенсивность $I$ возрастает, а степень циркулярной поляризации испытывает резонансное изменение, знак которого определяется спином оптически активного экситона, участвующего в гибридизации. Такое поведение наиболее отчетливо проявилось в экспериментах по анализу низкотемпературной фотолюминесценции в структурах с квантовыми ямами $\mathrm{GaAs} / \mathrm{Al}_{x} \mathrm{Ga}_{1-x} \mathrm{As}[28]$ и сверхрешетках GaAs/AlAs типа II [29-32].

Теория оптически детектируемого антипересечения экситонных уровней в полупроводниках в магнитном поле построена в работе [26]. На рис. 2 представлены результаты расчета интенсивности и циркулярной поляризации излучения экситонов $X_{e-h h}$ в сверхрешетке $\mathrm{GaAs} / \mathrm{AlAs}$ типа II. Описание антипересечения уровней осуществлялось путем введения низкосимметричного возмущения $\hat{V}$, смешивающего радиационные состояния с нерадиационными. Предполагалось, что оператор $\hat{V}$ действует на электронный и дырочный спин независимо, так что $\hat{V}=\hat{V}^{e}+\hat{V}^{h}, \hat{V}^{e}=\sigma_{+} V_{e}+\sigma_{-} V_{e}^{*}$,
$\hat{V}^{h}=\sigma_{+}^{h} V_{h}+\sigma_{-}^{h} V_{h}^{*}$, где $\sigma_{ \pm}=\left(\sigma_{x} \pm \mathrm{i} \sigma_{y}\right) / 2, \sigma_{\alpha}-$ спиновые матрицы Паули, $\sigma_{ \pm}^{h}=\left(\sigma_{x}^{h} \pm \mathrm{i} \sigma_{y}^{h}\right) / 2, \sigma_{\alpha}^{h}-$ псевдоспиновые матрицы Паули в базисе состояний тяжелых дырок $\pm 3 / 2$. Для учета квазирезонансного возбуждения экситонов вводились две скорости генерации: $G_{0}$ для темных состояний с $m= \pm 2$ и $G_{0}+G_{r}$ для светлых состояний с $m= \pm 1$. При расчете использовались экспериментально определенные обменные константы и $g$-факторы, а отношения $G_{r} / G_{0}$ и $\tau_{n r} / \tau_{r}$ подбирались из условия наилучшего согласия с зависимостью $P_{c}\left(B_{z}\right)$, измеренной в сверхрешетке $\mathrm{GaAs} / \mathrm{AlAs}$ 17.4/26 $\AA$ [31]. Анализ показывает, что существуют две независимые причины для появления циркулярной поляризации фотолюминесценции: 1) различие в скоростях генерации радиационных и нерадиационных состояний, 2) различие между временами жизни $\tau_{r} \tau_{n r} /\left(\tau_{r}+\tau_{n r}\right)$ и $\tau_{n r}$ экситона в этих состояниях. Если главную роль имеет первая причина, так что $G_{0} \tau_{n r}<G_{r} \tau_{r}$, то антипересечение сопровождается резонансным уменьшением интенсивности и модуля степени циркулярной поляризации. Если же главную роль играет различие времен жизни, так что $G_{0} \tau_{n r}>G_{r} \tau_{r}$, то антипересечение приводит к перекачке возбуждения с более заполненного нерадиационного состояния 3 к менее заполненному состоянию $j=1$ или 2 (рис. $1, a$ ), вследствие чего полная интенсивность $I$ и модуль $P_{c}$ возрастают. При выбранных значениях параметров выполняется неравенство $G_{0} \tau_{n r}>G_{r} \tau_{r}$ и, следовательно, реализуется второй сценарий, см. рис. $2, a$ и $2, b$, в согласии с экспериментом по анализу циркулярной поляризации в продольном магнитном поле [30-32].

Кристаллы $\mathrm{GaP}$, легированные медью. В этих материалах триплетный экситон $X_{\text {trip }}$ связан 
на глубоком примесном центре и излучает фотон с энергией $1.911 \mathrm{eV}$, заметно отличающейся от низкотемпературной ширины непрямой запрещенной зоны $2.32 \mathrm{eV}$. Для одного из образцов параметры экситона, входящие в гамильтониан (4) и определенные из сравнения с экспериментальными данными, составляют: $g_{\text {tr }}=2.05, \delta_{z}=+0.013 \mathrm{meV}, \delta_{x y}=0.0025 \mathrm{meV}$ [12]. Согласно (9) антипересечение уровней должно происходить при $B \sim 0.1 \mathrm{~T}$. В эксперименте [12] интенсивность ФЛ с ростом магнитного поля растет, достигает максимума в области $0.1 \mathrm{~T}$, а затем начинает спадать. По-видимому, это было первым наблюдением антипересечения экситонных уровней в полупроводниках.

Твердые растворы $\mathrm{CdS}_{1-x} \mathrm{Se}_{x}$. В низкотемпературных спектрах фотолюминесценции твердых растворов с замещением в анионной подрешетке наблюдается широкая полоса излучательной рекомбинации экситонов, локализованных на флуктуациях состава, и ee LO-повторения. B полупроводниках со структурой вюрцита (CdS, CdSe) основное состояние экситона образовано из тяжелой дырки и локализованный экситон относится к виду $X_{e-h h}$. Данные по поляризации ФЛ при резонансном возбуждении экситонов линейно и циркулярно поляризованным светом свидетельствуют о том, что в системе флуктуационных экситонов проявляется скрытая анизотропия: имеется не только расщепление между дублетами \pm 1 и $\pm 2\left(\delta_{0} \neq 0\right)$, но и между подуровнями светлого экситона $\left(\delta_{2} \neq 0\right)[13,33]$. Осциллирующие дипольные моменты экситонов на этих подуровнях, подуровни 1 и 2 на рис. 1, $a$, ориентированы вдоль осей $\eta$ и $\xi$, случайно распределенных в плоскости, перпендикулярной главной оси $z \| \mathrm{C}_{6}$. Из немонотонного поведения степени поляризации $P_{c}(B)$, обусловленного антипересечением экситонных подуровней, определены параметры спин-гамильтониана [34]: $\delta_{0}=0.62 \mathrm{meV}, \delta_{2}=0.25 \mathrm{meV}, g_{e}=1.8, g_{h h}=5.7$.

Кристаллы GaSe и твердые растворы $\mathrm{GaSe}_{1-x} \mathrm{Te}_{x}$. Локализованные экситоны в этих материалах имеют тонкую структуру триплетных экситонов $X_{\text {trip }}$. В работах $[35,36]$ методом спектроскопии с временни́м разрешением исследована временна́я зависимость сигнала антипересечения зеемановских подуровней в излучении триплетных локализованных экситонов в кристалле GaSe и полупроводниковом твердом растворе $\mathrm{GaSe}_{1-x} \mathrm{Te}_{x}$ в продольном магнитном поле в условиях неполяризованной накачки.

При стационарном оптическом возбуждении зависимость интенсивности фотолюминесценции $I$ от магнитного поля $B$ при фиксированном значении длины волны излучения содержит максимум, который является сигналом антипересечения уровней. При возбуждении коротким импульсом форма этого сигнала существенно меняется в течение времени $t$, отсчитываемого от момента возбуждения экситона. В момент $t=0$ сигнал антипересечения очень слабый, при увеличении $t$ в зависимости интенсивности экситонного излучения от магнитного поля формируется максимум (на этом этапе форма сигнала антипересечения аналогична форме, наблюдаемой в условиях стационарного возбуждения). С дальнейшим увеличением времени $t$ зависимость $I(B)$ превращается в двугорбую кривую. При теоретическом описании временно́й эволюции интенсивности $I(t)$ в $[35,36]$ вводилось локальное возмущение $V$, задаваемое матричными элементами $\left\langle m^{\prime}|V| m\right\rangle\left(m^{\prime} \neq m\right)$ и смешивающее экситонные состояния $|1\rangle,|0\rangle$ и $|-1\rangle$. Наилучшее согласие с экспериментом получено при следующих наборах параметров: $\delta_{z}=0.0357 \mathrm{meV}, g_{\mathrm{tr}}=1.7$, $\tau_{r}=0.125 \mu \mathrm{s}, \tau_{n r}=7 \mu \mathrm{s}, 2|\langle 0|V| \pm 1\rangle|=0.0045 \mathrm{meV}$ для GaSe и $\delta_{z}=0.05 \mathrm{meV}, g_{\text {tr }}=1.85, \tau_{r}=0.16 \mu \mathrm{s}, \tau_{n r}=10$ $\mu \mathrm{s}, 2|\langle 0|V| \pm 1\rangle|=0.008 \mathrm{meV}$ для $\mathrm{GaSe}_{0.87} \mathrm{Te}_{0.13}$.

Структуры с квантовыми точками и нанокристаллами. С понижением размерности перекрытие электронно-дырочных огибающих возрастает, а значит, растет и обменное взаимодействие. Поэтому в квантовых точках обменная константа $\delta_{0}$ для экситонов $X_{e-h h}$, меняясь в широких пределах, может достигать несколько миллиэлектронвольт [19,37].

В качестве исходной модели для предварительного анализа экспериментальных данных можно использовать модель раздела 2.А, в которой учитывается релаксация с верхних, светлых подуровней 1, 2 на нижние, темные подуровни, а обратными процессами пренебрегается. В этом случае для степени МЦПЛ светлых экситонов получим

$$
P_{c}=\frac{\left(g_{e}-g_{h h}\right) \mu_{B} B_{z}}{\varepsilon} \frac{\tau}{\tau+\tilde{\tau}_{s}} \tanh \left(\frac{\varepsilon}{2 k_{B} T}\right) .
$$

Здесь $\quad \varepsilon=\sqrt{\left[\left(g_{e}-g_{h h}\right) \mu_{B} B_{z}\right]^{2}+\delta_{2}^{2}}, \quad \tilde{\tau}_{s}=2 \tau_{s}[1+$ $\left.+\exp \left(-\varepsilon / k_{B} T\right)\right]^{-1}, \tau$ и $\tau_{s}-$ соответственно время жизни в экситонных состояниях 1,2 и время спиновой релаксации между ними, определенное так, что скорость переходов $1 \rightarrow 2$ с верхнего на нижний светлый подуровень равна $f_{1} / 2 \tau_{s}$, а скорость обратных переходов $2 \rightarrow 1$ равна $f_{2} \exp \left(-\varepsilon / k_{B} T\right) / 2 \tau_{s}, \quad$ где $f_{1}, f_{2}$ - заселенности. Такая модель применима для многих структур с квантовыми ямами, см. напр. [38-41]. В ряде случаев однако приходится использовать более сложные модели. Например, на величину МЦПЛ экситонов может оказывать влияние форма коллоидного нанокристалла CdTe в виде вытянутого или сплюснутого сфероида [42].

Наблюдать антипересечение экситонных подуровней удается в квантовых точках с небольшими значениями $\delta_{0}$, как это, например, было сделано в структуpax с самоорганизованными квантовыми точками InP, у которых $\delta_{0}=0.14 \mathrm{meV}$ [43]. С другой стороны, в сферических нанокристаллах и нанообъектах „точка-встержне“ $\mathrm{CdS} / \mathrm{CdSe}$ обменная константа $\delta_{0}$ составляет $2-5 \mathrm{meV}$, антипересечение возможно только в очень сильных полях; более того, при низкой температуре экситоны $X_{e-h h}$ скапливаются только на нижних, темных 
подуровнях 3, 4 и высвечиваются за счет отступления от стандартных правил отбора [19].

\section{4. Динамика и кинетика светлых и темных экситонов в ультратонкой квантовой яме GaAs/AIAs}

Явление МЦПЛ экситонов и многоэкситонных комплексов в непрямозонных объемных полупроводниках $\mathrm{Ge}$ и $\mathrm{Si}$ детально исследовалось в 70-ых годах прошлого столетия. Результаты этих исследований изложены в обзорной главе 6 коллективной монографии [44]. Мы рассмотрим это явление, а также зависимость интенсивности ФЛ от магнитного поля в структуре с одним мономолекулярным слоем GaAs, помещенным между слоями AlAs толщины $50 \mathrm{~nm}[20,21]$, см. также статью Шамирзаева в этом номере [22]. Эта структура дважды непрямая, т.е. непрямая и в реальном пространстве, и в k-пространстве, в ней локализованный экситон $X_{e-h h}$ образован из Г-дырки в слое GaAs и привязанного к ней кулоновским взаимодействием электрона из $X_{x}, X_{y}$ долин в слоях AlAs. Так как $g$-факторы электрона и дырки имеют один и тот же знак $\left(g_{e}, g_{h h}>0\right)$, то при низкой температуре в сильном продольном магнитном поле экситоны сосредоточены на оптически неактивном подуровне +2 или -2 . Поэтому они рекомбинируют преимущественно безызлучательно и ФЛ ослаблена, а так как времена излучательной и безызлучательной рекомбинации экситонов сильно различаются $\left(\tau_{n r} \gg \tau_{r}\right)$, то кинетика затухания низкотемпературной ФЛ замедлена. Как видно из рис. $3, a$, в отсутствие поля интенсивность ФЛ монотонно спадает с ростом температуры. Совсем иначе ведет себя зависимость $I(T)$ в магнитном поле $9 \mathrm{~T}$, рис. $3, b$ : при повышении температуры относительная заселенность светлых подуровней возрастает, что влечет за собой рост интенсивности ФЛ и ускорение ее кинетики. Так, при изменении температуры от 2 до $7 \mathrm{~K}$ интенсивность увеличивается в несколько раз. При более высоких температурах возрастает роль безызлучательной рекомбинации и интенсивность $I$ начинает спадать. Подчеркнем, что такое поведение ФЛ характерно для экситонов с совпадающими по знаку $g_{e}$ и $g_{h h}$. Если знаки $g$-факторов противоположны, как, например, в структуре с квантовой ямой $\mathrm{CdTe} / \mathrm{CdMgTe}$, то интенсивность ФЛ остается высокой вплоть до магнитных полей $B=45$ T [45].

Для описания зависимостей $I(B, T)$ и $P_{c}(B, T)$ в $[20,21]$ построена теория стационарной и разрешенной во времени ФЛ локализованных экситонов. Так как в исследованных наноструктурах типа II обменное взаимодействие мало и измерения проводились в сравнительно сильных магнитных полях, обменным расщеплением пренебрегалось и учитывался только зеемановский вклад (2) в экситонный спин-гамильтониан. На рис. 3,c круглыми стрелками показаны процессы релаксации между экситонными подуровнями, учитываются только переходы с изменением спина одной из частиц: $|s, j\rangle \rightarrow|-s, j\rangle$ или $|s, j\rangle \rightarrow|s,-j\rangle$. Влиянием магнитного поля на вероятности переходов с верхних уровней на нижние (на рис. $3, c W_{-1 / 2,1 / 2}$ и $W_{-3 / 2,3 / 2}$ ) пренебрегалось, а для переходов снизу вверх вводились больцмановские множители

$$
\begin{array}{r}
W_{1 / 2,-1 / 2}=\alpha W_{-1 / 2,1 / 2}, \quad \alpha=\exp \left(-\frac{g_{e} \mu_{B} B}{k_{\mathrm{B}} T}\right), \\
W_{3 / 2,-3 / 2}=\beta W_{-3 / 2,3 / 2}, \quad \beta=\exp \left(-\frac{g_{h h} \mu_{B} B_{z}}{k_{\mathrm{B}} T}\right) .
\end{array}
$$

Здесь рассмотрен общий случай наклонного магнитного поля $\mathbf{B}$, составляющего угол $\theta$ с осью $z$. При этом в выражения для $\alpha$ и $\beta$ входят соответственно полное магнитное поле $B$ и его проекция на ось $z$ (предполагаемая положительной), так как электронный $g$-фактор практически изотропен, а влиянием латеральной проекции поля на спин тяжелой дырки пренебрегается. Поэтому в рассматриваемом случае символ $s$ обозначает проекцию спина на направление поля, а символ $j-$ проекцию спина дырки на ось $z$. Вместо обозначения заселенности экситонного подуровня $f_{s j}$ мы для краткости используем обозначение $f_{k l}$, где $k=\operatorname{sign}(s)$ и $l=\operatorname{sign}(j)$. Система уравнений кинетики для $f_{k l}$ может быть представлена в виде

$$
\begin{aligned}
\frac{d f_{--}}{d t} & +\left(D^{2} w+w^{\prime}\right) f_{--}+w_{e}\left(\alpha f_{--}-f_{+-}\right) \\
& +w_{h}\left(\beta f_{--}-f_{-+}\right)=G_{--}, \\
\frac{d f_{++}}{d t} & +\left(D^{2} w+w^{\prime}\right) f_{++}+w_{e}\left(f_{++}-\alpha f_{-+}\right) \\
& +w_{h}\left(f_{++}-\beta f_{+-}\right)=G_{++}, \\
\frac{d f_{+-}}{d t} & +\left(C^{2} w+w^{\prime}\right) f_{+-}+w_{e}\left(f_{+-}-\alpha f_{--}\right) \\
& +w_{h}\left(\beta f_{+-}-f_{++}\right)=G_{+-}, \\
\frac{d f_{-+}}{d t}+ & \left(C^{2} w+w^{\prime}\right) f_{-+}+w_{e}\left(\alpha f_{-+}-f_{++}\right) \\
+ & w_{h}\left(f_{-+}-\beta f_{--}\right)=G_{-+} .
\end{aligned}
$$

Здесь $\quad w=1 / \tau_{r} \quad$ и $\quad w^{\prime}=1 / \tau_{n r}, \quad w_{e}=W_{-1 / 2,1 / 2}^{-1} \quad$ и $w_{h}=W_{-3 / 2,3 / 2}^{-1}, C=\cos (\theta / 2)$ и $D=\sin (\theta / 2), G_{k l}-$ скорость генерации экситонов на подуровень $k, l$. При нерезонансном возбуждении можно считать эту скорость одинаковой для всех подуровней: $G_{k l} \equiv G$. Интенсивности ФЛ, поляризованной по правому и левому кругу, связаны с заселенностями $f_{k l}$ соотношениями

$$
I_{+/-} \propto \frac{C^{2}}{\tau_{r}} f_{-+/+-}+\frac{D^{2}}{\tau_{r}} f_{++/--},
$$

откуда получаем выражение для степени поляризации

$$
P_{c}=\frac{C^{2}\left(f_{-+}-f_{+-}\right)+D^{2}\left(f_{++}-f_{--}\right)}{C^{2}\left(f_{-+}+f_{+-}\right)+D^{2}\left(f_{++}+f_{--}\right)} .
$$



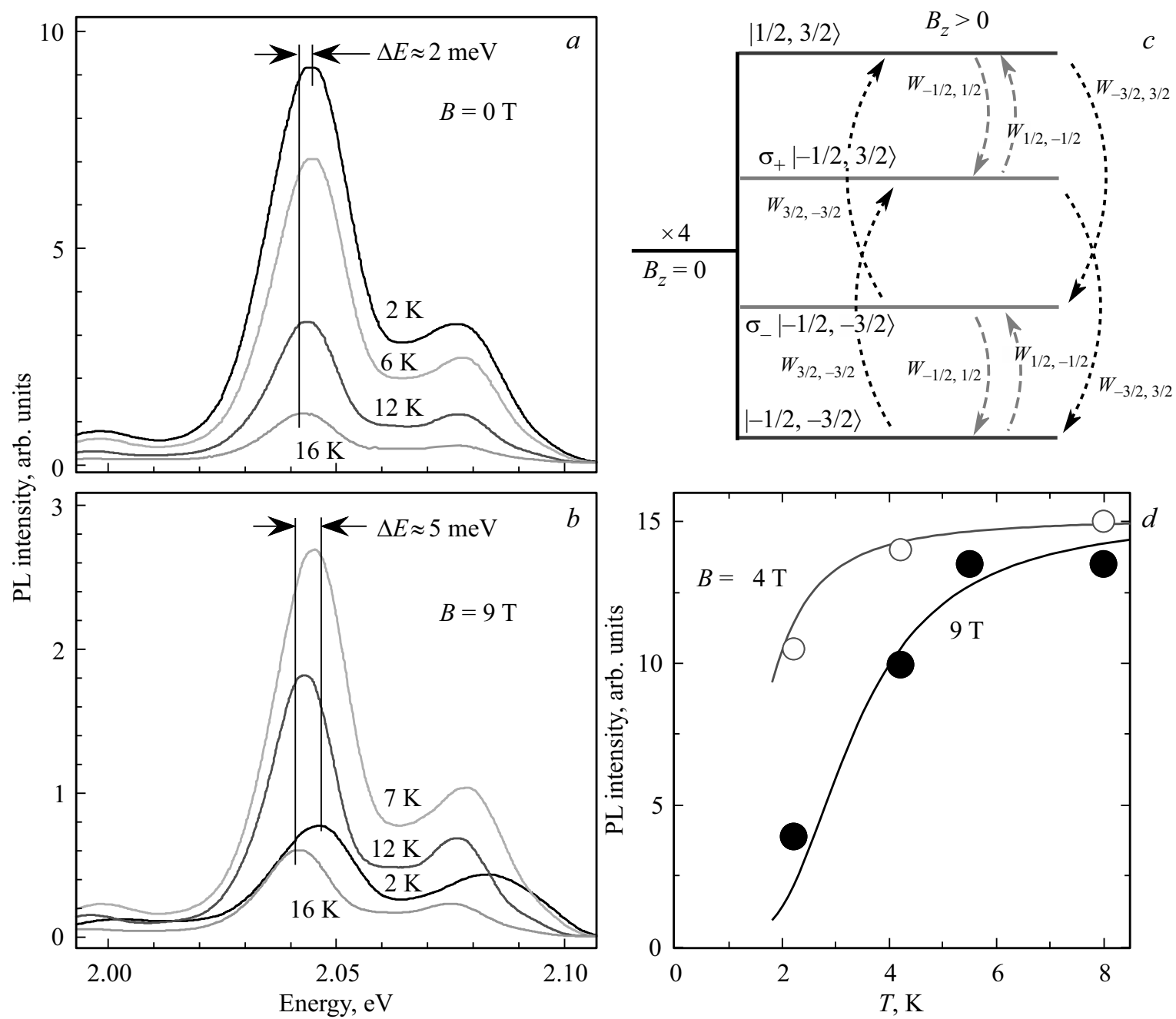

Рис. 3. Спектры ФЛ ультратонкой квантовой ямы GaAs/AlAs QW, измеренные в геометрии Фарадея при четырех температурах: (a) $B=0 \mathrm{~T},(b) B=9 \mathrm{~T}$. (c) Схематическое изображение учитываемых переходов (с испусканием или поглощением фононов) между экситонными подуровнями, расщепленными в магнитном поле. $(d)$ Интенсивность ФЛ в зависимости от температуры при $B=4 \mathrm{~T}$ и 9 Т (кружки). Сплошные кривые рассчитаны в рамках кинетической теории [20] при следующих параметрах: $\tau_{r}=0.34$ ms, $\tau_{n r}=8.5 \mathrm{~ms}, g_{e}=2, g_{h h}=3.5, w_{e}=w_{h}=1.25 \cdot 10^{5} \mathrm{~s}^{-1}$. [20]
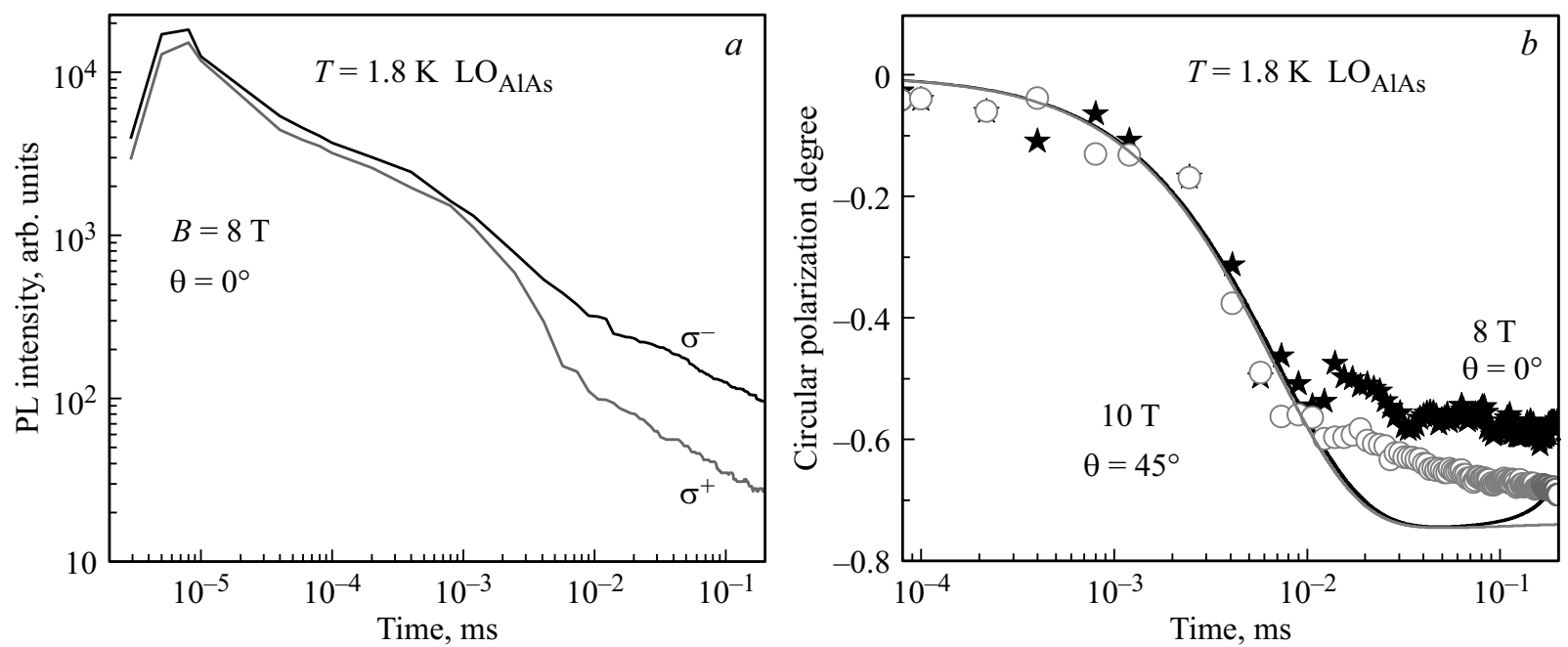

Рис. 4. (a) Затухание во времени $\sigma_{+}$и $\sigma_{-}$компонент $\mathrm{LO}_{\mathrm{AlAs}}$ фононного повторения ФЛ при импульсном оптическом возбуждении

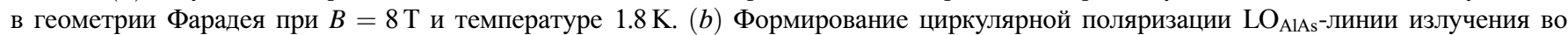
времени. Звездочки и кружки - эксперимент соответственно при $B=8 \mathrm{~T}$ в геометрии Фарадея и $B=10 \mathrm{~T}$ в наклонном поле с углом наклона $\theta=45^{\circ} .[21]$ 


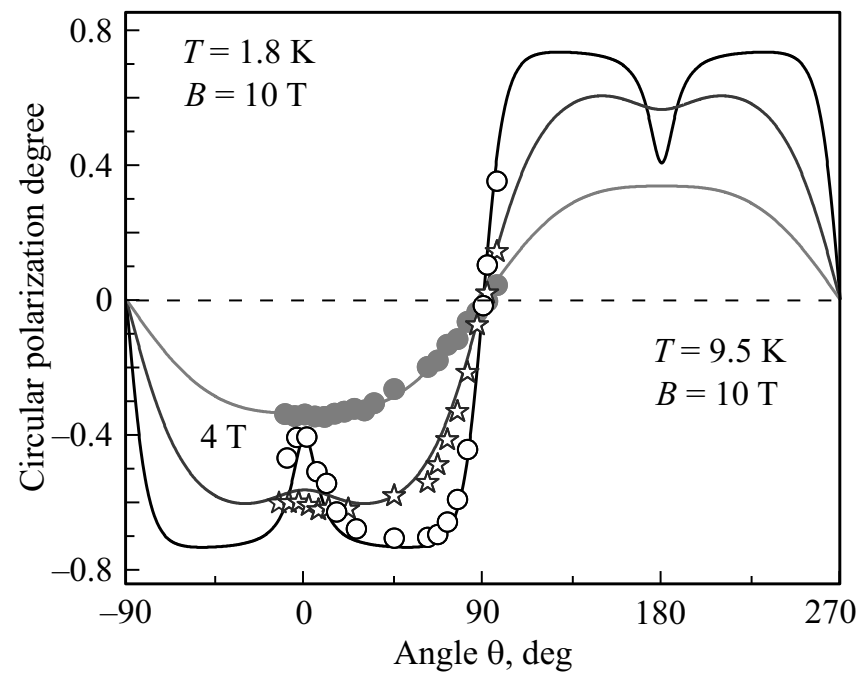

Рис. 5. Угловая зависимость МЦПЛ $P_{c}(\theta)$, измеренная при $T=1.8 \mathrm{~K}$ для $B=4 \mathrm{~T}$ (звездочки) и $10 \mathrm{~T}$ (открытые кружки) и при $T=9.5 \mathrm{~K}$ для $B=10 \mathrm{~T}$ (сплошные кружки). Кривые рассчитаны в рамках модели (12) при $\tau_{r}=0.34 \mathrm{~ms}, \tau_{n r}=8.5 \mathrm{~ms}$, $\tau_{s e}=\left(2 w_{e}\right)^{-1}=33 \mu \mathrm{s}, \tau_{s h}=\left(2 w_{h}\right)^{-1}=3 \mu \mathrm{s}[21]$.

При детальном сопоставлении с экспериментальными данными в [21] учитывалось небольшое нарушение правил отбора и выражение (14) было слегка модифицировано.

На рис. 3, $d$ результаты расчета сопоставлены с экспериментом по термоактивации экситонной ФЛ. Рис. 4 демонстрирует рекомбинационную динамику формирования МЦПЛ в продольном и косом магнитных полях. Анализ показывает, что время нарастания модуля $\left|P_{c}\right|$ определяется исключительно наименьшим из времен спиновой релаксации $\left(2 w_{e}\right)^{-1}$ и $\left(2 w_{h}\right)^{-1}$, а знак $P_{c}-$ отношением $w_{h} / w_{e}$, которое в изученных образцах было много больше единицы. При низкой температуре МЦПЛ обнаруживает нетривиальную немонотонную угловую зависимость $P_{c}(\theta)$, рис. 5 .

\section{5. МЦПЛ экситонов и трионов в двумерных системах}

Взаимодействие экситонов с носителями заряда, электронами или дырками, в полупроводниковых двумерных системах приводит к образованию заряженных трехчастичных комплексов - триона $\mathrm{X}^{-}$[46] (аналог отрицательно заряженного иона водорода $\mathrm{H}^{-}$[7]), состоящего из двух электронов и одной дырки, или триона $\mathrm{X}^{+}$, состоящего из двух дырок и одного электрона. В низкотемпературных спектрах ФЛ легированных (а иногда и не легированных специально) двумерных структур наблюдаются две линии, экситонная и трионная, см. например [47-51].

А. Сосуществование экситонов и трионов в квантовых ямах. В отсутствие магнитного поля или в не очень сильном поле спины двух одинаковых частиц антипараллельны и обменное взаимодействие между ними и спином неспаренной частицы отсутствует. МЦПЛ трионов определяется селективным заполнением спиновых подуровней неспаренной частицы и для трионов с тяжелой дыркой описывается формулами

$$
\begin{gathered}
P_{c}\left(X_{h h}^{-}\right)=-\frac{\tau}{\tau+\tilde{\tau}_{s, h h}} \tanh \left(\frac{\varepsilon_{h h}}{2 k_{B} T}\right), \\
P_{c}\left(X_{h h}^{+}\right)=\frac{\tau}{\tau+\tilde{\tau}_{s, e}} \tanh \left(\frac{\varepsilon_{e}}{2 k_{B} T}\right) .
\end{gathered}
$$

Здесь $\varepsilon_{h h}=g_{h h} \mu_{B} B_{z}, \varepsilon_{e}=g_{e} \mu_{B} B_{z}$, и при $\varepsilon_{e}, \varepsilon_{h h}>0$

$$
\begin{gathered}
\tilde{\tau}_{s, h h}=2 \tau_{s, h h}\left[1+\exp \left(-\varepsilon_{h h} / k_{B} T\right)\right]^{-1}, \\
\tilde{\tau}_{s e}=2 \tau_{s, e}\left[1+\exp \left(-\varepsilon_{e} / k_{B} T\right)\right]^{-1},
\end{gathered}
$$

где $\tau_{s, e}$ и $\tau_{s, h h}-$ времена спиновой релаксации электрона и тяжелой дырки. При выводе (15) предполагается, что скорость генерации трионов не зависит от спинового состояния триона. В этом случае знаки циркулярной поляризации ФЛ экситона, триона $\mathrm{X}^{-}$и триона $\mathrm{X}^{+}$определяются соответственно знаками величин $g_{e}-g_{h h},-g_{h h}$ и $g_{e}$. Это, в частности, означает, что при противоположных знаках $g_{e}-g_{h h}$ и $-g_{h h}$ степени поляризации излучения экситона и триона $\mathrm{X}^{-}$также противоположны, как это наблюдалось в спектрах ФЛ квантовой ямы $\mathrm{CdTe} / \mathrm{Cd}_{0.7} \mathrm{Mg}_{0.3} \mathrm{Te}$ [48]. С ростом магнитного поля $g$-фактор тяжелой дырки в данной структуре изменяет знак при $B=12 \mathrm{~T}$, и следом за ним меняется направление поляризации $P_{c}\left(X_{h h}^{-}\right)$.

Продольное магнитное поле существенно влияет на перераспределение интенсивностей ФЛ экситонов и трионов. Это происходит, во-первых, потому, что синглетный трион может образоваться только при условии противоположных направлений спинов резидентного электрона и электрона в экситоне и, во-вторых, в магнитном поле спиновые подуровни экситона заселены селективно, и температура меняет эти заселенности. Так, в квантовой яме $\mathrm{CdTe} / \mathrm{Cd}_{0.7} \mathrm{Mg}_{0.3} \mathrm{Te}$ в отсутствие поля при $T=1.6 \mathrm{~K}$ экситонная линия ФЛ уступает по интенсивности трионной линии, но в поле $B=5$ Т экситонный и трионный вклады в $\sigma_{-}$компоненту ФЛ становятся сравнимыми по величине [45]. С ростом температуры от 1.6 до $16 \mathrm{~K}$ перераспределение заселенности между экситонными подуровнями приводит к тому, что трионная линия опять преобладает над экситонной [50]. В очень сильных полях в спектрах ФЛ начинает проявляться триплетный трион с полным спином спаренных электронов $S=1[45,52]$.

Обратим внимание на схожесть явления МЦПЛ у экситонов, связанных на нейтральных донорах в объемных полупроводниках, и трионов в структурах с квантовыми ямами, выращенными на основе этих полупроводников $[11,53]$. 

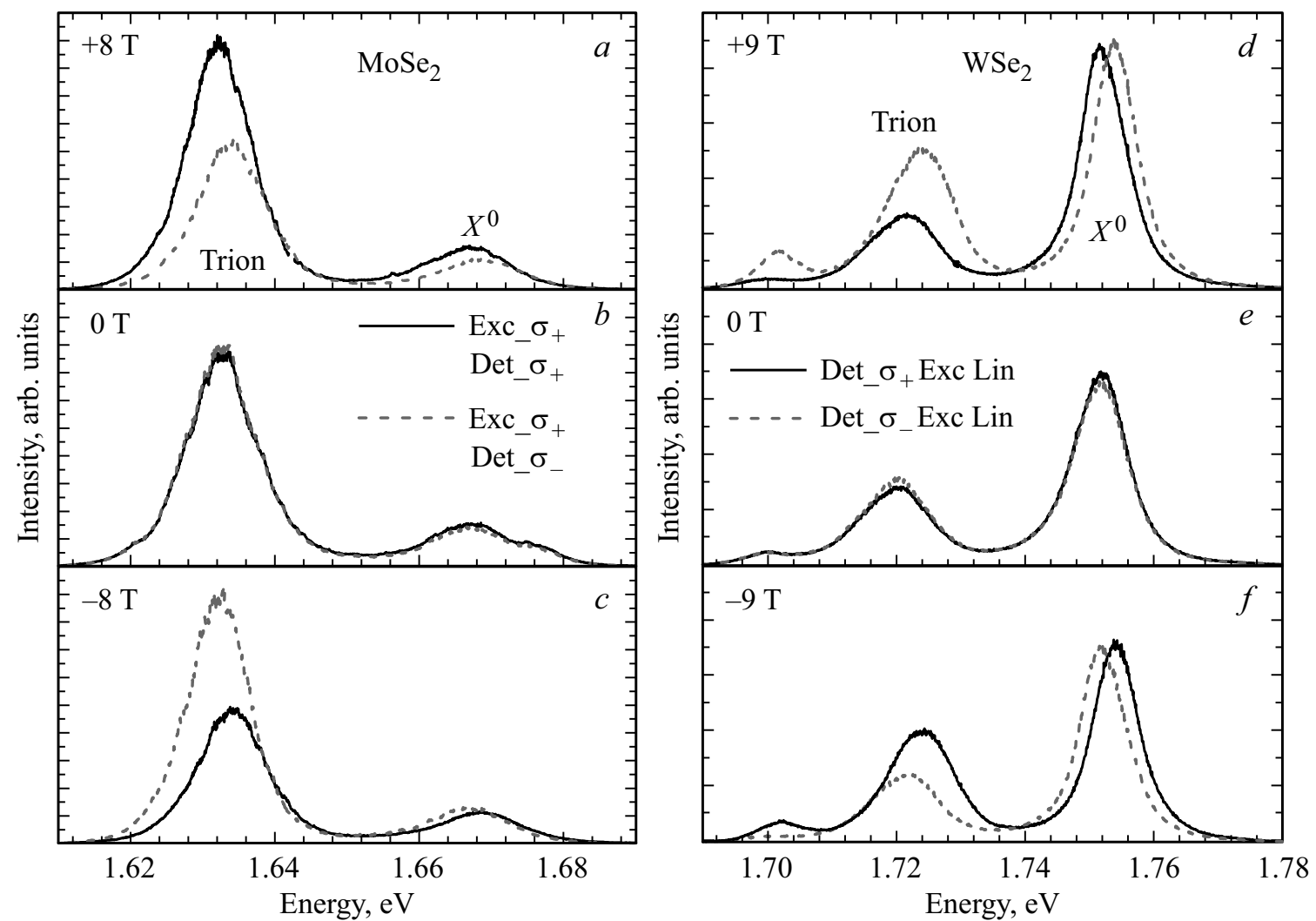

Рис. 6. Спектры ФЛ, измеренные в $\sigma_{+}$(сплошные кривые) и $\sigma_{-}$(пунктир) поляризациях в монослое $\mathrm{MoSe}_{2}$ при циркулярно поляризованном возбуждении (левая панель) и в монослое $\mathrm{WSe}_{2}$ при линейно поляризованном возбуждении (правая панель). $(b)$ и $(e)$ - измерения в отсутствие магнитного поля; $(a)$ и $(c)-$ измерения при $B_{z}=8 \mathrm{~T}$ и $-8 \mathrm{~T} ;(d)$ и $(f)-$ измерения при $B_{z}=9 \mathrm{~T}$ и -9 Т $[56]$.

\section{В. МЦПЛ в двумерных дихалькогенидах переходных} металлов. В последние годы активно исследуются двумерные полупроводниковые соединения нового класса - дихалькогениды переходных металлов с химической формулой $\mathrm{MX}_{2}$, где $\mathrm{M}$ - это молибден или вольфрам, а X - сера или селен. Они обладают прямой запрещенной зоной в видимой части электромагнитного спектра. Дно зоны проводимости и потолок валентной зоны располагаются в вершинах $\mathrm{K}_{+}$и $\mathrm{K}_{-}$шестиугольной зоны Бриллюэна, экситонные линии наблюдаются в спектре ФЛ даже при комнатной температуре. Наряду с экситонной наблюдается и трионная линия излучения.

Мономолекулярные слои $\mathrm{MX}_{2}$ характеризуются точечной симметрией $\mathrm{D}_{3 h}$, а точечная симметрия группы волнового вектора $\mathrm{K}_{+}$или $\mathrm{K}_{-}-\mathrm{C}_{3 h}$. При симметрии $\mathrm{C}_{3 h}$ спин-орбитальное взаимодействие полностью снимает спиновое вырождение в точках экстремума, при этом в соответствии с симметрией к инверсии времени знаки спинового расщепления в долинах $\mathrm{K}_{+}$и $\mathrm{K}_{-}$ противоположны. Во всех четырех материалах $\mathrm{MoS}_{2}$, $\mathrm{WS}_{2}, \mathrm{MoSe}_{2}$ и $\mathrm{WSe}_{2}$ спиновое расщепление валентной зоны $\Delta_{v}$ велико и превышает $100 \mathrm{meV}$, а расщепление $\Delta_{c}$ принимает значения от нескольких $\mathrm{meV}$ до нескольких десятков $\mathrm{meV}[54,55]$. В молибдатах знаки $\Delta_{c}$ и $\Delta_{v}$ противоположны, а в вольфраматах они совпадают. Междузонные оптические переходы идут с сохранением спина для света циркулярной поляризации $\sigma_{+}$в одной долине и $\sigma_{-}$в другой. Далее мы рассматриваем экситонные переходы с участием дырки, находящейся в основном спиновом состоянии (А-экситоны). Такие переходы при разных знаках $\Delta_{c}$ и $\Delta_{v}$ являются оптически активными для электрона, находящегося также в основном состоянии. Если знаки спиновых расщеплений совпадают, то светлым является состояние экситона с электроном на верхнем спиновом подуровне. Но в обоих случаях измерение циркулярно поляризованной компоненты ФЛ позволяет определять вклад во вторичное излучение определенной долины.

В продольном магнитном поле к энергии экситона добавляется зеемановская энергия $\left(g_{e} s_{z}^{e}+g_{h} s_{z}^{h}\right) \mu_{B} B_{z}$, пик полосы $\sigma_{ \pm}$экситонной люминесценции сдвигается на $\pm \delta_{Z} / 2$, так что относительный сдвиг этих полос составляет $\delta_{Z}$, где $\delta_{Z}=\left|\left(g_{e}-g_{h}\right) \mu_{B} B_{z}\right|$. В работе [56] проведено сравнительное исследование магнитооптических свойств двумерных диселенидов молибдена и вольфрама. Измеренные поляризованные спектры ФЛ представлены на рис. 6. В монослое $\mathrm{MoSe}_{2}$ магнитная циркулярная поляризация наблюдается как на экситонной, так и на трионной полосе (рис. 6, $a$ ), тогда как в $\mathrm{WSe}_{2}$ интегральная интенсивность экситонной полосы в магнитном поле остается неполяризованной, рис. $6, d$. Такое различие в поведении экситонов объясняется разными знаками $\Delta_{c}$ 
в этих двух материалах. В монослое $\mathrm{MoSe}_{2}$ основное состояние экситона является светлым и за время жизни часть экситонов совершают переход из долины с положительной зеемановской энергией $\delta_{Z} / 2$ в долину с зеемановской энергией $-\delta_{Z} / 2$. В монослое $\mathrm{WSe}_{2}$ такое перетекание произойти не успевает, так как светлый экситон, будучи возбужденным экситонным состоянием, быстрее сваливается в основное, оптически неактивное состояние.

В условиях эксперимента [57] можно было менять легирование монослоя $\mathrm{WSe}_{2}$ и переходить от образца $p$-типа к образцу $n$-типа, в промежутке получая образец c нулевой концентрацией носителей заряда. Энергия связи триона $X^{+}$оказалась равной $21 \mathrm{meV}$, а трион $X^{-}$ проявился в виде двух спектральных пиков с энергиями связи 29 и $35 \mathrm{meV}$. Анализ показывает [57], что трион $X^{+}$, который вносит вклад в ФЛ, образован из синглетного состояния двух дырок, расположенных по одной в долинах $\mathrm{K}_{+}$и $\mathrm{K}_{-}$, и неспаренного электрона в верхнем спиновом состоянии, а пики излучения триона $X^{-}$связаны со следующими трехчастичными состояниями: 1) два электрона с противоположными спинами и неспаренная дырка, находящиеся в одной и той же долине, и 2) электроны с параллельными спинами в разных долинах, т.е. один в основном спиновом состоянии, а другой в возбужденном, и неспаренная дырка в той долине, в которой электрон находится на верхнем спиновом подуровне.

\section{6. Дополнительные механизмы МЦПЛ, связанные с экситонами}

В этом разделе мы кратко рассмотрим особые механизмы формирования циркулярной поляризации экситонного излучения.

А. Экситонные магнитные поляроны. В полумагнитных полупроводниках обменное взаимодействие локализованных носителей заряда с магнитными ионами приводит к формированию экситонного магнитного полярона. В объемном образце такой полярон может возникнуть только при заметной исходной немагнитной локализации, тогда как для формирования магнитного полярона в двумерной структуре достаточно небольшой затравочной локализации экситона [58].

Изучение МЦПЛ позволяет получить независимую оценку размеров магнитного полярона. Так, в работе [59] использовались три метода для определения радиуса $r_{0}$ полярона в эпитаксиальных слоях $\mathrm{Cd}_{1-x} \mathrm{Mn}_{x} \mathrm{Te}$. $\mathrm{B}$ поляризационном методе учитывалось, что объем полярона $V=(4 \pi / 3) r_{0}^{3}$ связан с производной $\theta=\left(d P_{c} / d B_{z}\right)_{B_{z}=0}$ от степени циркулярной поляризации ФЛ по магнитному полю соотношением, формула (7) в [59],

$$
V=\frac{\pi k_{B} T \theta^{2}}{2 \chi}
$$

где $\chi-$ вклад в спиновую восприимчивость магнитных ионов в отсутствие внешнего поля. В образцах с составом $x=0.07-0.39$ производная $\theta$ уменьшалась от
4.44 до 1.05. Полученная зависимость $r_{0}$ от состава $x$ оказалась в хорошем согласии с определением $r_{0}$ из оценки энергии магнитного полярона по формуле (4) в [59]. Измерение величины $\theta=9.2 \mathrm{~T}^{-1}$ в квантовых ямax $\mathrm{Cd}_{0.935} \mathrm{Mn}_{0.065} \mathrm{Te} / \mathrm{Cd}_{0.83} \mathrm{Mg}_{0.17} \mathrm{Te}$ позволило определить энергию магнитного полярона $E_{\mathrm{MP}}=13 \pm 3 \mathrm{meV}$ в согласии со значением $E_{\mathrm{MP}}=12 \pm 1 \mathrm{meV}$, полученным путем измерения разности между энергией фотона и спектральным пиком вторичного излучения при резонансном оптическом возбуждении локализованных экситонов [58]. При этом немагнитный вклад в энергию локализации экситона составляет всего $4 \mathrm{meV}$. Анализ полевой зависимости МЦПЛ позволяет выделить два режима индуцированной внешним полем поляризации ФЛ, получивших в [60] название „парамагнитная область“ и „спин-стекольная область“.

В. Экситонные поляритоны в продольном магнитном поле. Экситонные поляритоны в планарных оптических микрорезонаторах обладают важным свойством: компонента волнового вектора поляритонов в плоскости структуры сохраняется при их туннелировании через зеркало (распределенный брэгговский отражатель) в вакуум и превращении в фотоны. Поэтому распределение экситонных поляритонов и их динамику можно исследовать экспериментально по отражению, рассеянию, пропусканию и люминесценции, проводя спектральные измерения интенсивности света, испускаемого под разными углами из микрорезонатора. Экситонные поляритоны в микрорезонаторе, будучи бозонами, при пространственном ограничении свободного движения и достижении критических условий могут испытывать конденсацию, близкую к явлению бозе-эйнштейновской конденсации, см. например, обзор [61].

Поляритон с экситоном $X_{e-h h}$ имеет спиновую степень свободы, проекциям спина \pm 1 отвечают циркулярно поляризованные состояния. Вследствие эффектов обменного межчастичного взаимодействия основное состояние конденсированной экситонной фазы оказывается линейно поляризованной, т.е. когерентной суперпозицией циркулярных компонент $\sigma_{+}$и $\sigma_{-}$. В работе [62] при исследовании МЦПЛ обнаружено, что в спинорном конденсате экситонных поляритонов в микрорезонаторе с квантовыми ямами GaAs и брэгговскими отражателями $\mathrm{Al}_{0.2} \mathrm{Ga}_{0.8} \mathrm{As} / \mathrm{AlAs}$ зеемановское расщепление спиновых компонент подавляется вплоть до некоторых критических величин магнитного поля, которое определяется разностью энергий взаимодействия между бозе-частицами с одинаковой и противоположной ориентациями спинов. Иное поведение поляритонного конденсата в аналогичной структуре наблюдалось в работе [63]: конденсация происходила для каждой спиновой компоненты при различных значениях критической мощности $Q_{\mathrm{th}}$, и разность $Q_{\mathrm{th}}^{-}-Q_{\mathrm{th}}^{+}$критических значений для $\sigma_{-}$и $\sigma_{+}$компонент возрастала с ростом магнитного поля. В работе [64] измерения зависимости расщепления спин-поляризованных поляритонных состояний от плотности мощности лазерной накачки в 
магнитном поле показали, что изменения фактически не выходят за пределы экспериментальной ошибки и не превышают 15\% от величины расщепления. Слабая зависимость зеемановского расщепления от накачки в работе [65] связывается с низкой скоростью спиновой релаксации между спиновыми подуровнями, а также с тем, что система, состоящая из газа экситонов в резервуаре и конденсата поляритонов, далека от термодинамического равновесия. В работе [65] исследованы спектры фотолюминесценции экситонных поляритонов в микрорезонаторах в зависимости от плотности оптического возбуждения и магнитного поля. Обнаружено, что при повышении концентрации экситонов в фиксированном магнитном поле или при увеличении магнитного поля при фиксированной концентрации экситонов все экситоны собираются на нижнем спиновом уровне энергии, хотя зеемановское расщепление составляет всего $0.15 \mathrm{meV}$, что меньше тепловой энергии $k_{B} T=$ $0.5 \mathrm{meV}$. Такое возможно, если химический потенциал системы экситонных поляритонов обращается в нуль, т. е. происходит их конденсация.

С. Поляризация ФЛ параэкситонов в $\mathrm{Cu}_{2} \mathrm{O}$ в магнитном поле. Основное состояние экситона $\Gamma_{6}^{+} \times \Gamma_{7}^{+}$в результате обменного взаимодействия расщепляется на орто- и параэкситон. В параэкситоне спины электрона и дырки антипараллельны и полный спин равен нулю. Это экситонное состояние $\Gamma_{2}^{+}$невырождено, оно не испытывает зеемановского расщепления в магнитном поле и, казалось бы, ожидать циркулярной поляризации излучения параэкситона не приходится. Тем не менее, Гастевым и др. [17] наведенная магнитным полем круговая поляризация была обнаружена на полосе $\mathrm{B}_{1}$ фононного повторения с испусканием фонона $\Gamma_{5}^{-}$. Матричный элемент перехода для экситона $\Gamma_{2}^{+}$с учетом линейных по магнитному полю В членов можно записать в виде

$$
M\left(\Gamma_{2}^{+}\right)=F\left(\mathbf{e}^{*} \cdot \mathbf{u}\right)+\mathrm{i} G\left(\mathbf{B} \cdot\left[\mathbf{e}^{*} \times \mathbf{u}\right]\right),
$$

где $\mathbf{e}-$ вектор поляризации излучаемого света, $u_{x}, u_{y}, u_{z}$ - амплитуды фононов представления $\Gamma_{5}^{-}$, преобразующиеся как $x\left(y^{2}-z^{2}\right), y\left(z^{2}-x^{2}\right), z\left(x^{2}-y^{2}\right), F$ и $G$ - вещественные коэффициенты. Коэффициент $F$ мал, так как матричный элемент (17) при $B=0$ отличен от нуля только при учете подмешивания к состояниям $\Gamma_{6}^{+}$и $\Gamma_{7}^{+}$волновых функций из других зон за счет спин-орбитального взаимодействия. Из формулы (17) следует, что интенсивности право- и левополяризованных компонент ФЛ в направлении поля пропорциональны $(F \mp G B)^{2}$, а степень циркулярной поляризации равна

$$
P_{c}\left(B_{1}\right)=-\frac{2 F G B}{F^{2}+G^{2} B^{2}} .
$$

Причиной появления линейных по $B$ членов в матричном элементе (17) является магнитоиндуцированное смешивание состояния параэкситона $\Gamma_{2}^{+}$с состояниями ортоэкситона $\Gamma_{5}^{+}$, для которого переходы с излучением фононов $\Gamma_{5}^{-}$разрешены и не имеют малости при $B=0$.

\section{7. Заключение}

За четыре десятилетия исследований магнитная циркулярная поляризация фотолюминесценции экситонов сформировалась как самостоятельный раздел экситонной физики. Выяснены основные механизмы ее формирования. Конечно, при изучении очень узких экситонных линий излучения отдельной квантовой точки, наблюдаемого современным методом оптической микроспектроскопии, не требуется прибегать к теории поляризованной фотолюминесценции большого ансамбля центров локализации экситонов или квантовых точек. Тем не менее, эта теория по-прежнему востребована. Развитие технологии вызывает появление все новых полупроводниковых наносистем, для описания поляризации излучения которых приходится или модифицировать установленные механизмы, или разрабатывать дополнительные механизмы МЦПЛ. Преимуществом методики МЦПЛ является ее относительная простота: а) для определения степени циркулярной поляризации достаточно поставить перед фотоприемником циркулярный анализатор и измерить интенсивность излучения при двух положениях анализатора, б) в отличие от оптической ориентации она не требует резонансного возбуждения, в) она не требует спектрального разрешения зеемановских подуровней экситона и может быть применена к широкому классу объектов со спектрально широкими линиями или полосами ФЛ, г) несмотря на простоту, эта методика может дать богатую информацию о $g$-факторах, временах жизни и спиновой релаксации экситонов, д) наконец, она удобна для идентификации экситонных комплексов.

Автор выражает благодарность С.Ю. Вербину, М.М. Глазову, В.П. Кочерешко, А.Н. Резницкому и Д.Р. Яковлеву за полезное обсуждение рукописи.

\section{Список литературы}

[1] Я.И. Френкель. ЖЭТФ 6, 647 (1936); УФН 93, 408 (1967).

[2] А.С. Давыдов. Изв. АН СССР. Сер. физ. 12, 608 (1948).

[3] С.И. Пекар. Избранные труды. Наук. думка, Киев (1988). $512 \mathrm{c}$.

[4] Е.Ф. Гросс. УФН 63, 576 (1957).

[5] Э.И. Рашба. В кн.: Экситоны. Гл. 13. / Под ред. Э.И. Рашбы, М.Д. Стерджа. Наука, М. (1985). 616 c.; [Excitons. NorthHolland (1982)].

[6] Е.Ф. Гросс, Б.С. Разбирин, М.А. Якобсон. ЖТФ 27, 1149 (1957).

[7] M.A. Lampert. Phys. Rev. Lett. 1, 450 (1958).

[8] J.R. Haynes. Phys. Rev. Lett. 4, 361 (1960).

[9] R.E. Dietz, D.G. Thomas, J.J. Hopfield. Phys. Rev. Lett. 8, 391 (1962).

[10] D.G. Thomas, J.J. Hopfield. Phys. Rev. 128, 2135 (1962).

[11] A.V. Rodina, M. Strassburg, M. Dworzak, U. Haboeck, A. Hoffmann, A. Zeuner, H.R. Alves, D.M. Hofmann, B.K. Meyer. Phys. Rev. B 69, 125206 (2004).

[12] H.P. Gislason, B. Monemar, P.J. Bean, B.C. Herbert, S. Depinna, B. C. Cavenett, N. Killoran. Phys. Rev. B 26, 827 (1982).

[13] S. Pemogorov, A. Reznitsky, S. Verbin, V. Lysenko. Solid State Commun. 47, 5 (1983). 
[14] D. Gammon, E.S. Snow, B.V. Shanabrook, D.S. Katzer, D. Park. Phys. Rev. Lett. 76, 3005 (1996).

[15] С.В. Гупалов, Е.Л. Ивченко, А.В. Кавокин. ЖЭТФ 113, 703 (1998).

[16] K.J. Moore, G. Duggan, P. Dawson, C.T. Foxon. Phys. Rev. B 38, 5535 (1988).

[17] R. Heitz, M. Grundmann, N.N. Ledentsov, L. Eckey, M. Veit, D. Bimberg, V.M. Ustinov, A.Yu. Egorov, A.E. Zhukov, P.S. Kop'ev, Zh.I. Alferov. Appl. Phys. Lett. 68, 361 (1996).

[18] Feng Liu, L. Biadala, A.V. Rodina, D.R. Yakovlev, D. Dunker, C. Javaux, J.-P. Hermier, A.L. Efros, B. Dubertret, M. Bayer. Phys. Rev. B 88, 035302 (2013).

[19] B. Siebers, L. Biadala, D.R. Yakovlev, A.V. Rodina, T. Aubert, Z. Hens, M. Bayer. Phys. Rev. B 91, 155304 (2015).

[20] T.S. Shamirzaev, J. Debus, D.R. Yakovlev, M.M. Glazov, E.L. Ivchenko, M. Bayer. Phys. Rev. B 94, 045411 (2016).

[21] T.S. Shamirzaev, J. Rautert, D.R. Yakovlev, J. Debus, A.Yu. Gornov, M.M. Glazov, E.L. Ivchenko, M. Bayer. Phys. Rev. B 96, 035302 (2017).

[22] Т.С. Шамирзаев. ФТТ 60, 8, 1510 (2018).

[23] С.В. Гастев, Е.Л. Ивченко, Г.Е. Пикус, Н.С. Соколов, Н.Л. Яковлев. ФТТ 25, 3002 (1983).

[24] Е.Ф. Гросс, Н.А. Каррыев. ДАН СССР 84, 471 (1952).

[25] E.L. Ivchenko. Phys. Status Solidi A 164, 487 (1997).

[26] Е.Л. Ивченко, А.Ю. Каминский. ФТТ 37, 1418 (1995).

[27] D.R. Yakovlev, A.V. Platonov, E.L. Ivchenko, V.P. Kochereshko, C. Sas, W. Ossau, L. Hansen, A. Waag, G. Landwehr, L.W. Molenkamp. Phys. Rev. Lett. 88, 257401 (2002).

[28] E. Blackwood, M.J. Snelling, R.T. Barley, S.R. Andrews, C.T.B. Foxon. Phys. Rev. B 50, 14246 (1994).

[29] J.M. Trombetta, T.A. Kennedy, W. Tseng, D. Gammon. Phys. Rev. B 43, 2458 (1991).

[30] П.Г. Баранов, И.В. Машков, Н.Г. Романов, К. Гордон, Ф. Лаваллар, Р. Планель. Письма в ЖЭТФ 60, 429 (1994).

[31] N.G. Romanov, P.G. Baranov, I.V. Mashkov, P. Lavallard, R. Planel. Solid-State Electron 37, 911 (1994).

[32] П.Г. Баранов, Н.Г. Романов, И.В. Машков, Г. Хитрова, Х.М. Гиббс, О. Лунгнес. ФТТ 37, 2991 (1995).

[33] С.Ю. Вербин, С.А. Пермогоров, А.Н. Резницкий. ФТТ 25, 346 (1983).

[34] A. Reznitsky, S. Verbin, S. Permogorov, A. Kornievsky, L. Tenishev, A.Yu. Kaminskii, H. Gerlach, M. Grün, M. Hetterich, C. Klingshirn. Proc. 23rd Int. Conf. Physics of Semicond. Berlin, Germany (1996). 349 p.

[35] A.N. Starukhin, D.K. Nelson, B.S. Razbirin. Phys. Rev. B 65, 193204 (2002)

[36] А.Н. Старухин, Д.К. Нельсон, Б.С. Разбирин, Д.Л. Федоров, Д.К. Сюняев. ФТТ 57, 1888 (2015).

[37] L. Biadala, B. Siebers, R. Gomes, Z. Hens, D.R. Yakovlev, M. Bayer. J. Phys. Chem. C 118, 22309 (2014).

[38] M. Chamarro, C. Gourdon, P. Lavallard. J. Lumin. 70, 222 (1996).

[39] L. Langof, L. Fradkin, E. Ehrenfreund, E. Lifshitz, O.I. Micic, A.J. Nozik. Chem. Phys. 297, 93 (2004).

[40] S. Lee, M. Dobrowolska, J.K. Furdyna. J. Crystal Growth 275, e2301 (2005).

[41] L. Turyanska, J.H. Blokland, U. Elfurawi, O. Makarovsky, P.C.M. Christianen, A. Patanè. Phys. Rev. B 82, 193302 (2010).

[42] Feng Liu, A.V. Rodina, D.R. Yakovlev, A. Greilich, A.A. Golovatenko, A.S. Susha, A.L. Rogach, Yu.G. Kusrayev, M. Bayer. Phys. Rev. B 89, 115306 (2014).

[43] Y. Masumoto, Ken Toshiyuki, T. Suzuki, M. Ikezawa. Phys. Rev. B 77, 115331 (2008).
[44] Г.Е. Пикус, Е.Л. Ивченко. В кн.: Экситоны. Гл. 6. / Под ред. Э.И. Рашбы, М.Д. Стерджа. Наука, М. (1985). 616 с.; [Excitons. North-Holland (1982)].

[45] D. Andronikov, V. Kochereshko, A. Platonov, T. Barrick, S.A. Crooker, G. Karczewski. Phys. Rev. B 72, 165339 (2005).

[46] K. Kheng, R.T. Cox, Y. Merle d'Aubigne, F. Bassani, K. Saminadayar, S. Tatarenko. Phys. Rev. Lett. 71, 1752 (1993).

[47] D.R. Yakovlev, J. Puls, G.V. Mikhailov, G.V. Astakhov, V.P. Kochereshko, W. Ossau, J. Nürnberger, W. Faschinger, F. Henneberger, G. Landwehr. Phys. Status Solidi A 178, 501 (2000).

[48] C.R.L.P.N. Jeukens, P.C.M. Cristianen, J.C. Maan, D.R. Yakovlev, W. Ossau, V.P. Kochereshko, T. Wojtowicz, G. Karczewski, J. Kossut. Phys. Rev. B 66, 235318 (2002).

[49] J.G. Tischler, A.S. Bracker, D. Gammon, D. Park. Phys. Rev. B 66, 081310 (2002).

[50] Д.А. Андроников, М. Fehr, В.П. Кочерешко, S.A. Crooker, G. Karczewski. ФTT 49, 1492 (2007).

[51] M. Lorenzon, S. Christodoulou, G. Vaccaro, J. Pedrini, F. Meinardi, I. Moreels, S. Brovelli. Nature Commun. 6, 6434 (2015).

[52] G.V. Astakhov, D.R. Yakovlev, V.V. Rudenkov, P.C.M. Christianen, T. Barrick, S.A. Crooker, A.B. Dzyubenko, W. Ossau, J.C. Maan, G. Karczewski, T. Wojtowicz. Phys. Rev. B 71, 201312 (2005).

[53] J. Puls, S. Sadofev, F. Henneberger. Phys. Rev. B 85, 041307 (2012).

[54] K. Kośmider, J.W. González, J. Fernández-Rossier. Phys. Rev. B 88, 245436 (2013).

[55] A. Kormányos, G. Burkard, M. Gmitra, J. Fabian, V. Zólyomi, N.D. Drummond, V. Fal'ko. 2D Mater. 2, 022001 (2015).

[56] G. Wang, L. Bouet, M.M. Glazov, T. Amand, E.L. Ivchenko, E. Palleau, X. Marie, B. Urbaszek. 2D Mater. 2, 0340022 (2015).

[57] E. Courtade, M. Semina, M. Manca, M.M. Glazov, C. Robert, F. Cadiz, G. Wang, T. Taniguchi, K. Watanabe, M. Pierre, W. Escoffier, E.L. Ivchenko, P. Renucci, X. Marie, T. Amand, B. Urbaszek. Phys. Rev. B 96, 085302 (2017).

[58] I.A. Akimov, T. Godde, K.V. Kavokin, D.R. Yakovlev, I.I. Reshina, I.V. Sedova, S.V. Sorokin, S.V. Ivanov, Yu.G. Kusrayev, M. Bayer. Phys. Rev. B 95, 155303 (2017).

[59] K.V. Kavokin, I.A. Merkulov, D.R. Yakovlev, W. Ossau, G. Landwehr. Phys. Rev. B 6016499 (1999).

[60] А.В. Кудинов, Ю.Г. Кусраев, В.Н. Якимович. ФТТ 37, 660 (1995).

[61] В.Б. Тимофеев, ФТП 46, 865 (2012).

[62] A.V. Larionov, V.D. Kulakovskii, S. Höfling, C. Schneider, L. Worschech, A. Forchel. Phys. Rev. Lett. 105, 256401 (2010).

[63] C. Sturm, D. Solnyshkov, O. Krebs, A. Lemaitre, I. Sagnes, E. Galopin, A. Amo, G. Malpuech, J. Bloch. Phys. Rev. B 91, 155130 (2015).

[64] А.С. Бричкин, С.И. Новиков, А.В. Черненко, К. Шнайдер, С. Хёфлинг. ЖЭТФ 151, 883 (2017).

[65] В.П. Кочерешко, Д.В. Авдошина, P. Savvidis, S.I. Tsintzos, Z. Hatzopoulos, A.V. Kavokin, L. Besombes, H. Mariette. ФТП 50, 1527 (2016).

Редактор Ю.Э. Китаев 